STRUCTURAL BIOLOGY

ISSN 2059-7983

Received 9 March 2020

Accepted 4 June 2020

Edited by J. R. Helliwell, University of Manchester, United Kingdom

Keywords: macromolecular crystallography; beamline; double crystal/multi-layer monochromator; Canadian Light Source.

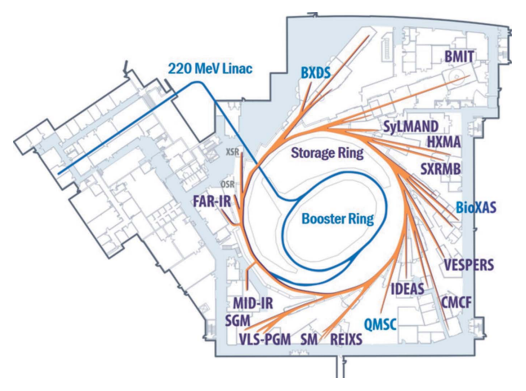

\section{Macromolecular crystallography beamlines at the Canadian Light Source: building on success}

\author{
Michel Fodje, Kiran Mundboth, Shaunivan Labiuk, Kathryn Janzen, James Gorin, \\ Denis Spasyuk, Scott Colville and Pawel Grochulski*
}

Canadian Macromolecular Crystallography Facility, Canadian Light Source, 44 Innovation Boulevard, Saskatoon, SK S7N 2V3, Canada. *Correspondence e-mail: pawel.grochulski@lightsource.ca

The Canadian Macromolecular Crystallography Facility (CMCF) consists of two beamlines dedicated to macromolecular crystallography: CMCF-ID and CMCFBM. After the first experiments were conducted in 2006, the facility has seen a sharp increase in usage and has produced a significant amount of data for the Canadian crystallographic community. Upgrades aimed at increasing throughput and flux to support the next generation of more demanding experiments are currently under way or have recently been completed. At CMCF-BM, this includes an enhanced monochromator, automounter software upgrades and a much faster detector. CMCF-ID will receive a major upgrade including a new undulator, a new monochromator and new optics to stably focus the beam onto a smaller sample size, as well as a brand-new detector.

\section{Introduction}

The Canadian Macromolecular Crystallography Facility (CMCF) operates two beamlines, CMCF-ID (08ID-1) and CMCF-BM (08B1-1), at the Canadian Light Source (Grochulski et al., 2011; Fodje et al., 2014). Located at the southeast corner of the facility (Fig. 1), both beamlines are moving towards full automation and now operate almost exclusively through remote access. About 70 crystallography groups are supported, including Canadian, American and international groups. The facility is dedicated to providing approximately $25 \%$ of the available beamtime to commercial projects and, at least on CMCF-ID, this is fully utilized primarily through remote control of the beamline or the mailin crystallography service, which is managed by a dedicated industrial team.

In 2016 the facility marked its tenth year of crystallography experiments, and 2017 saw the publication of the 1000th structure in the Protein Data Bank (https://www.rcsb.org/) as well as the 500th peer-reviewed publication using data collected at the facility. Now, after 13 years of successful operation, the facility is undergoing a series of upgrades aimed at increasing throughput and flux, while decreasing sample spot size, in order to support more challenging experiments that will include smaller sample sizes and serial crystallography using, for example, crystal-on-crystal chips or injectors.

\section{CMCF-ID upgrade}

The CMCF-ID upgrade secured Canada Foundation for Innovation (CFI) funding in 2015 to increase the beam flux, 
Table 1

Specifications of the CMCF beamlines before and after the planned upgrades.

Flux estimates are shown for a ring current of $220 \mathrm{~mA}$.

\begin{tabular}{|c|c|c|c|}
\hline & Current CMCF-ID & Planned CMCF-ID & Current $\mathrm{CMCF}-\mathrm{BM}$ \\
\hline Spectral range $(\mathrm{keV})$ & $6.5-18.0$ & $5.0-20.0$ & $5-20$ \\
\hline \multicolumn{4}{|l|}{ Energy bandwidth $(\Delta E / E)$} \\
\hline $\mathrm{Si}(111)$ & $\sim 1.5 \times 10^{-4}$ & $\sim 1.5 \times 10^{-4}$ & $\sim 1.5 \times 10^{-4}$ \\
\hline \multicolumn{4}{|l|}{ Flux on the sample (photons $\mathrm{s}^{-1}$ ) } \\
\hline At $12 \mathrm{keV}$ & $\begin{array}{l}2 \times 10^{12}(100 \mu \mathrm{m}) \\
1 \times 10^{12}(50 \mu \mathrm{m}) \\
5 \times 10^{11}(20 \mu \mathrm{m}) \\
2 \times 10^{10}(5 \mu \mathrm{m})\end{array}$ & $\begin{array}{l}>1.5 \times 10^{13}(100 \mu \mathrm{m}) \\
>1 \times 10^{13}(50 \mu \mathrm{m}) \\
>5 \times 10^{12}(20 \mu \mathrm{m}) \\
>1 \times 10^{12}(5 \mu \mathrm{m}) \\
\sim 5 \times 10^{14}(50 \mu \mathrm{m}) D M M\end{array}$ & $>1.5 \times 10^{11}$ \\
\hline At $8.1 \mathrm{keV}$ & & & $\begin{array}{l}>1.5 \times 10^{11} \mathrm{Si}(111) \\
>2.5 \times 10^{12} \mathrm{DMM}\end{array}$ \\
\hline Focal size at $12 \mathrm{keV}(\mu \mathrm{m} \times \mu \mathrm{m})$ & $150(\mathrm{H}) \times 30(\mathrm{~V})$ & $55(\mathrm{H}) \times 5(\mathrm{~V})$ & $210(\mathrm{H}) \times 190(\mathrm{~V})$ \\
\hline Beam crossfire at the sample at $12 \mathrm{keV}$ (no pinhole) $(\mathrm{mrad} \times \mathrm{mrad})$ & $0.9(\mathrm{H}) \times 0.2(\mathrm{~V})$ & $1.82(\mathrm{H}) \times 0.34(\mathrm{~V})$ & $1.95(\mathrm{H}) \times 0.30(\mathrm{~V})$ \\
\hline
\end{tabular}

reduce the beam focus size for micro-beam capabilities, improve the stability of the endstation and improve dataacquisition throughput.

The design philosophy was dictated by the inherent limitations of the CLS storage ring, especially the very large horizontal emittance. Therefore, a horizontally focusing mirror located close to the sample position was selected in order to maximize the demagnification ratio and provide a fixed horizontal focus at the sample. In the vertical direction, a secondary source and a dynamically focusing mirror close to the sample were chosen so that a variable vertical beam size of $5-50 \mu \mathrm{m}$ could be achieved. To significantly increase the flux density of the beamline, the $1.5 \mathrm{~m}$ long in-vacuum undulator (IVU) will be replaced with a longer $3.8 \mathrm{~m}$ IVU (Research

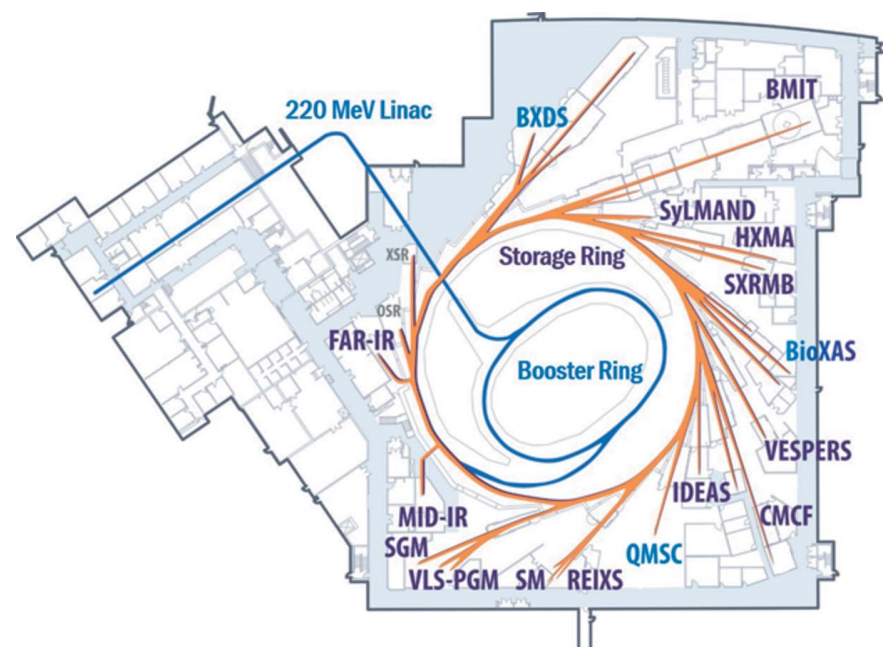

Figure 1

Schematic representation of the major components of the Canadian Light Source. The $2.9 \mathrm{GeV}$ storage ring has a circumference of $170.88 \mathrm{~m}$ and currently operates with a maximum current of $220 \mathrm{~mA}$. The horizontal emittance is approximately $22.7 \mathrm{~nm} \mathrm{rad}$, with a vertical emittance of $0.1017 \mathrm{~nm}$ rad. Operational beamlines which can support structural biology and biophysics projects include the Canadian Macromolecular Crystallography Facility (CMCF) and the BioMedical Imaging and Therapy (BMIT), Mid Infrared Spectromicroscopy (MID-IR) and Biological X-ray Absorption Spectroscopy (BioXAS) facilities.
Instruments). The width of the undulator magnets were optimized such that the effect of transverse nonlinear field roll-off seen by the electron beam is negligible. In isolation, the relatively low field and short period of the undulator, compared with the wigglers in the storage ring, will not have a detrimental focusing effect. The optical layout of the beamline will be changed and the endstation will be replaced. The new optics will feature a double-crystal/multilayer monochromator (DCMM; Axilon) and three new mirror systems (FMB Oxford). The vertically and horizontally focusing mirrors act in a Kirkpatrick-Baez (KB) configuration; however, they are located in different vacuum chambers owing to space restrictions. The third mirror can be dynamically bent to adjust the beam focus to the requested pinhole size to maximize flux. All three mirrors have rhodium/iridium coatings, except for the first mirror, which also has a silicon stripe for higher harmonic rejection. The r.m.s. slope errors are $0.37,0.78$ and $0.15 \mu \mathrm{rad}$, respectively. Together with the new undulator, this will enable the beamline to achieve a focus spot size of $5 \times 55 \mu \mathrm{m}$ with a photon flux of more than $10^{13}$ photons $^{-1}$ or up to $5 \times$ $10^{14}$ photons s$^{-1}$ in the double multi-layer (DMM) mode $(1 \%$ $\triangle E / E)$. In the DMM mode, the tunability of the monochromator is limited to the $7.2-10.4 \mathrm{keV}$ range (Table 1 ). The multilayer mirrors are arranged in series with the $\mathrm{Si}(111)$ crystals and will consist of two flat silicon substrates coated with 300 bilayers of $\mathrm{Mo} / \mathrm{B}_{4} \mathrm{C}$ and bearing r.m.s. slope errors of $0.3 \mu \mathrm{rad}$. The new layout of the beamline is shown in Fig. 2 and the results of ray tracing are shown in Fig. 3. The configuration will allow the energy to be extended down to $5 \mathrm{keV}$, allowing the possibility of S-SAD work. A detailed technical design of the beamline and optics specifications will be published elsewhere.

The current PILATUS3 S 6M detector will be replaced with an EIGER X 9M detector, while the high-capacity ISARA automounter, which was installed in 2017 , will continue to be a key component of the upgraded beamline.

In April 2019, the technical design report was completed. All major components have been procured and have either been received or are currently being received. The CMCF-ID beamline was closed for upgrades starting during the facility 
Table 2

\begin{tabular}{lll}
\hline & CMCF-BM & CMCF-ID \\
\hline 2017 & MxDC and MxLIVE updates & MxDC and MxLIVE updates \\
& & ISARA automouter installed \\
2018 & & $\begin{array}{l}\text { Preliminary design report completed } \\
\text { All major components procured }\end{array}$ \\
2019 & SAM performance upgrades & $\begin{array}{l}\text { Delivery of new IVU, EIGER detector and MD2S } \\
\text { microdiffractometer endstation }\end{array}$ \\
& DCMM monochromator upgrade & Shutdown for installation and commissioning \\
2020 & Installation of PILATUS S 6M detector & Full user operations \\
2021 & &
\end{tabular}

Timeline for the CMCF beamline-upgrade projects.

multilayers for the CMCF-BM beamline consist of two flat silicon substrates arranged in series with the $\mathrm{Si}(111)$ crystals and bear r.m.s. slope errors of $0.23 \mu \mathrm{rad}$. However, a coating of $\mathrm{Ni}_{93} \mathrm{~V}_{7} / \mathrm{B}_{4} \mathrm{C}$ with 500 bilayers was chosen. The distances of the optical components and beamline did not change from the original design (Fodje et al., 2014). The DMM operates at a fixed energy of $8.157 \mathrm{keV}$, with a $0.37 \%$

shutdown period in spring 2020, at which time the installation of the new insertion device and other components began. Installation and commissioning are expected to last about six months, with an anticipated return to service in January 2021. A summary of the upgrade timeline is shown in Table 2. To alleviate the loss of beam time to users during this period, most experiments will be accommodated on the CMCF-BM beamline, which has also been revamped in preparation for the increased demand.

\section{CMCF-BM upgrade}

In the summer of 2019, the CMCF-BM beamline doublecrystal monochromator (DCM) was upgraded to include a double multi-layer monochromator (DMM), enabling a highflux mode. In a similar manner to the CMCF-ID beamline, the $\triangle E / E$ energy bandpass. The DMM has already been commissioned and an 18-fold increase in flux over the DCM was observed at the sample. The high-flux mode is ideal for native experiments. Experiments requiring a higher energy resolution continue to be supported with the traditional Si(111) DCM. The high-flux mode has been available for use since September 2019. An example of a $1^{\circ} \mathrm{s}^{-1}$ frame from a thaumatin crystal is shown in Fig. 4. The diffraction patterns are readily analysed and integrated using the standard software pipeline already available at the beamline. Initial comparisons of both modes show that similar or better quality wavelength (Table 3). A more detailed comparative analysis will be described in a future publication.

To complement the faster collection times that are now possible on the beamline, the efficiency of the Stanford native data can be obtained for the same crystal at the same

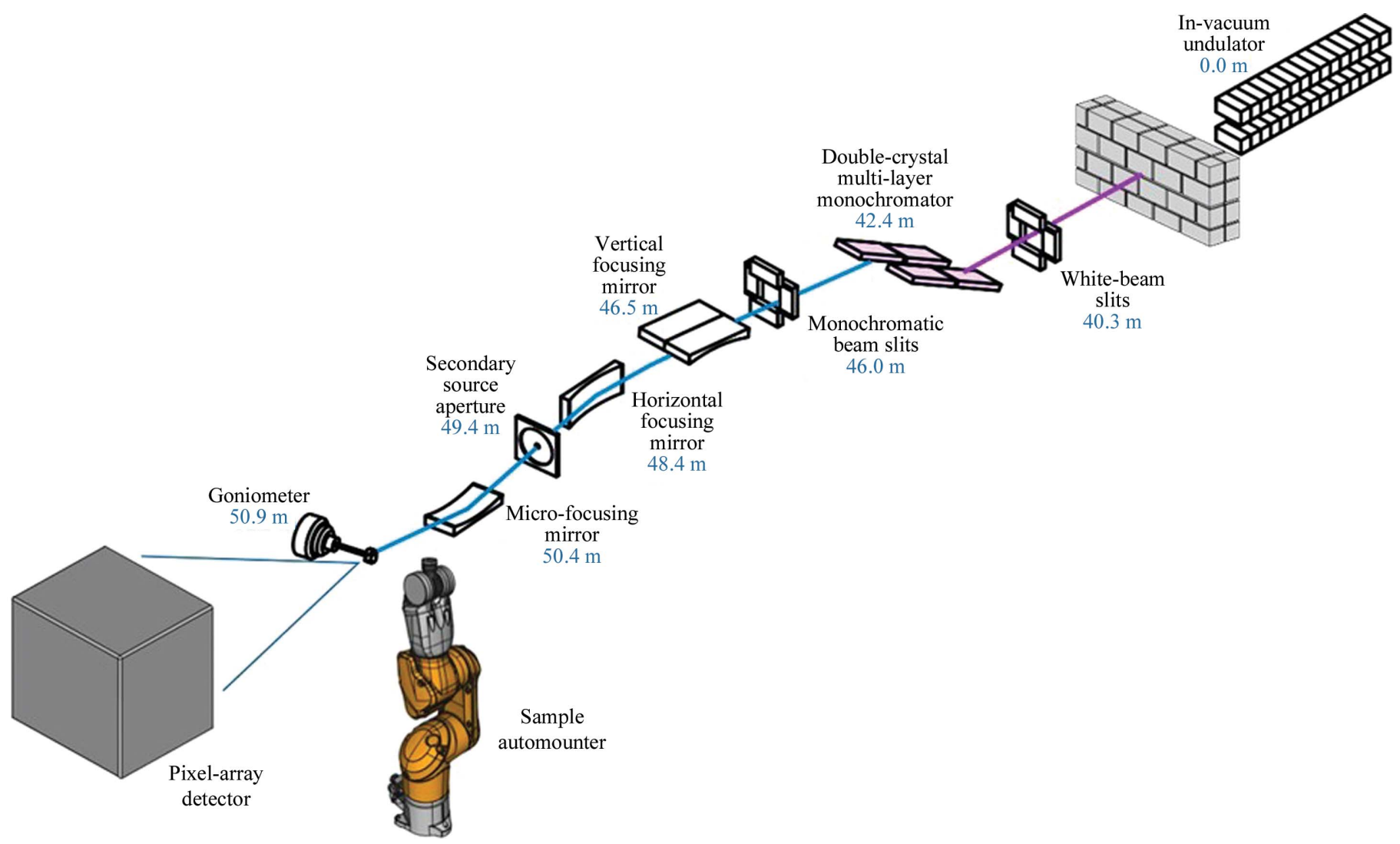

Figure 2

Optical layout of the planned CMCF-ID beamline. Absolute distances of the main components from the centre of the straight section of the ring are also included 
Automated Mounter (SAM) has been increased to become more comparable with the ISARA automounter at CMCF-ID.

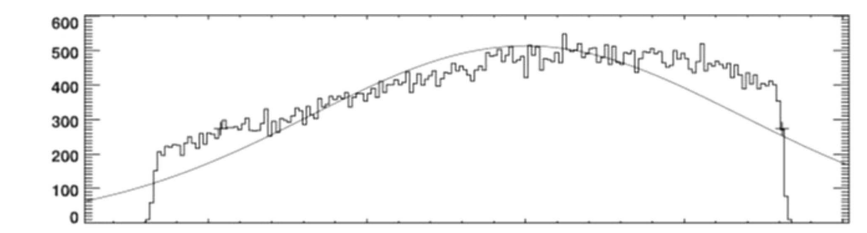

Beam divergence at sample Intensity $=39.5 \%$ $\Delta x^{\prime}$ (edge) $=2 \mathrm{mrad}$ $\Delta \mathrm{y}^{\prime}(\mathrm{FWHM})=0.5 \mathrm{mrad}$
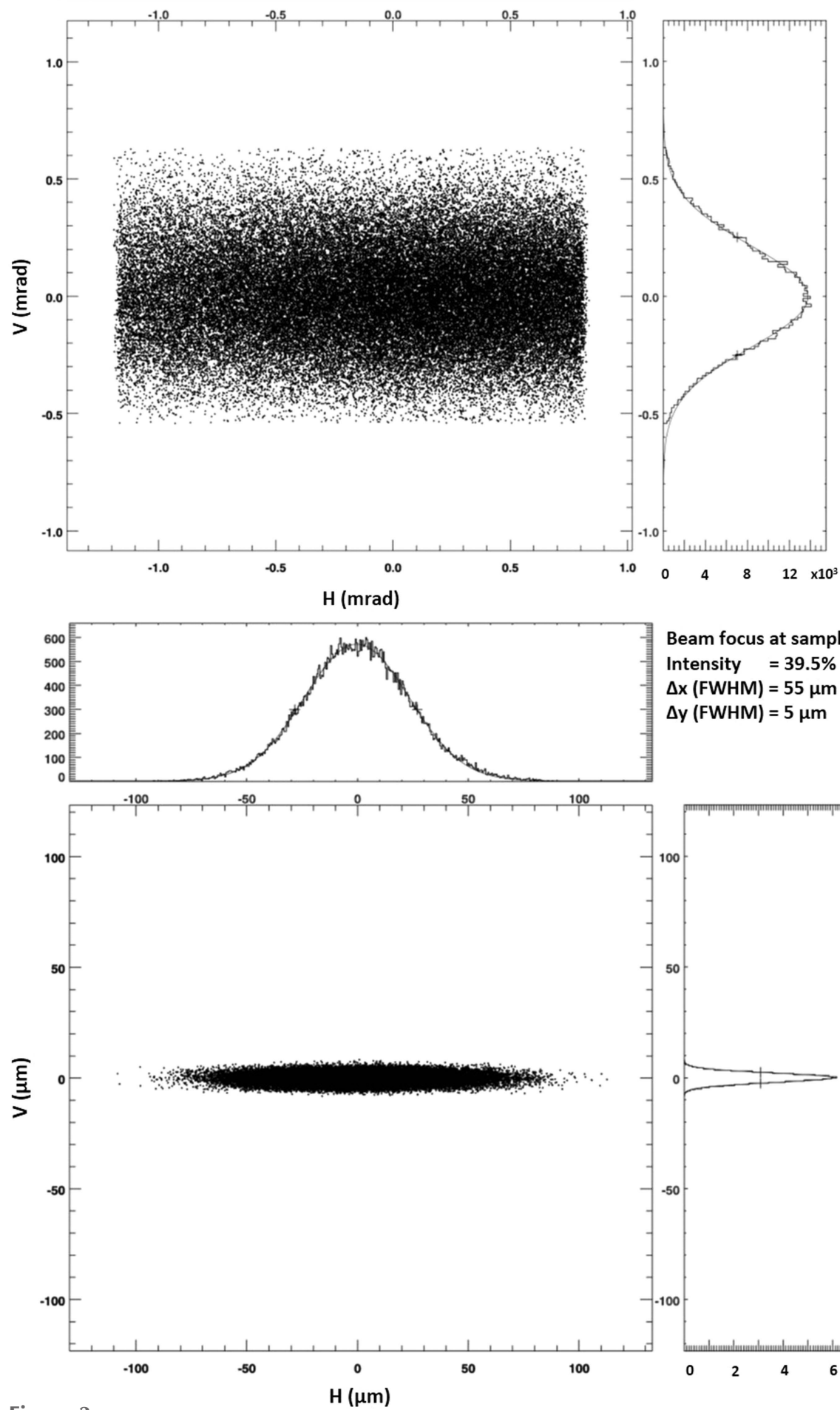

Beam focus at sample Intensity $=39.5 \%$ $\Delta x(F W H M)=55 \mu \mathrm{m}$ $\Delta y(F W H M)=5 \mu m$

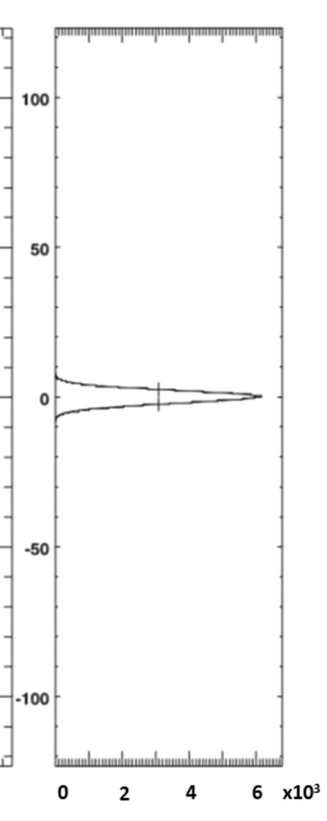

Figure 3

Result of ray-tracing for the CMCF-ID upgrade performed at $12 \mathrm{keV}$. Top, beam divergence; bottom, focus spot size at the sample position.
The software updates on the SAM automounter now support a duty cycle of as low as $25 \mathrm{~s}$ (previously $2.5 \mathrm{~min}$ ). Also, the PILATUS3 S 6M detector from CMCF-ID will be permanently moved to CMCF-BM, while CMCF-ID is equipped with the new EIGER $\mathrm{X} 9 \mathrm{M}$ detector.

\section{Computing and software}

Data acquisition, automated data processing, sample information management and data access are supported through the $M x D C, M x L I V E$ and AutoProcess software packages developed in-house (Fodje et al., 2012). In 2019, the computing and storage infrastructure was upgraded to provide more storage capacity with faster access. Specifically, the storage server was upgraded from an $18 \mathrm{~Tb}$ RAID system with spinning discs connected through a 4 Gbps network to a 45 Tb SSD RAID system with $20 \mathrm{Gbps}$ network access. Also, the ten-year-old 96-core compute cluster for data analysis was upgraded to more recent hardware with faster processors, providing a total of 336 cores. New versions of $M x D C$ and $M x L I V E$ were deployed to support the new capabilities.

Raw data collected at CMCF beamlines are stored under users' personal accounts on a network file system and are backed up in real time on the upgraded storage server. Files are maintained at the $\mathrm{CMCF}$ for as long as data-storage limitations allow, which is typically up to one year. Data downloads are facilitated through users' MxLIVE accounts.

Remote control of the beamlines is provided through the NoMachine client. Dedicated NoMachine servers for each beamline accept connections from a list of allowed users which is managed through MxLIVE. These connections provide the user with a desktop identical to that of a physical computer at the beamline, with full access to the CMCF computing infrastructure.

Demand for remote access in Canada has only grown since the first remote experiments were completed in 2011, and now accounts for about $85 \%$ of user access. Roughly $70 \%$ of remote-access experiments are completed through 
Table 3

Data-collection statistics for a thaumatin test crystal comparing the DCM [Si(111)] and DMM (multi-layer) modes.

Owing to the much higher flux for the DMM mode, the lowest available transmission of $10 \%$ was used for comparison. Statistics for the highest resolution shell are shown in parentheses. The data were processed using XDS (Kabsch, 2010) and data quality was assessed using Phenix (Liebschner et al., 2019).

\begin{tabular}{lll}
\hline & $\mathrm{Si}(111)$ mode & Multi-layer mode \\
\hline Wavelength $(\AA)$ & 1.52 & 1.52 \\
Data collection & 720 frames at $0.5^{\circ}$ per $0.5 \mathrm{~s}$ & 720 frames at $0.5^{\circ}$ per $0.5 \mathrm{~s}$ \\
Beam properties & $100 \mu \mathrm{m}$ aperture, $100 \%$ transmission & $100 \mu \mathrm{m}$ aperture, $10 \%$ transmission \\
Resolution range $(\AA)$ & $9.948-2.100(2.174-2.100)$ & $9.996-2.100(2.174-2.100)$ \\
Space group & $P 4_{1} 22_{1} 2$ & $P 4_{1} 22_{1}^{2}$ \\
Unit-cell parameters $\left(\AA{ }^{\circ}\right)$ & $a=b=57.97, c=150.48$, & $a=b=57.66, c=149.69$, \\
& $\alpha=\beta=\gamma=90$ & $\alpha=\beta=\gamma=90$ \\
Total reflections & $370297(35371)$ & $367652(35140)$ \\
Unique reflections & $13558(1318)$ & $13352(1297)$ \\
Multiplicity & $27.3(26.8)$ & $27.5(27.1)$ \\
Completeness $(\%)$ & $98.53(99.01)$ & $98.62(100.0)$ \\
Mean $I / \sigma(I)$ & $20.06(3.31)$ & $26.96(10.18)$ \\
Wilson $B$ factor $\left(\AA^{2}\right)$ & 30.13 & 23.17 \\
$R_{\text {merge }}$ & $0.1647(2.326)$ & $0.1217(0.8305)$ \\
$R_{\text {meas }}$ & $0.1678(2.372)$ & $0.124(0.8465)$ \\
$R_{\text {p.i.m. }}$ & $0.03203(0.4588)$ & $0.02355(0.1625)$ \\
CC & $0.997(0.928)$ & $0.998(0.986)$ \\
\hline
\end{tabular}

(Caveney et al., 2019) and antimalaria antibody research (McLeod et al., 2019).

The transition from researchers having to come onsite to collect data to data collection via remote control of the beamlines has been largely facilitated by the annual CLS Mx Data Collection School. This event is hosted by CMCF staff and takes place at the Canadian Light Source, normally during a week in the spring or summer months. A series of lectures, as well as hands-on exercises, allow participants to be actively engaged in data collection while experiencing synchrotron-facility life first-hand. Crystallographers from the University of Saskatchewan support the school by mentoring participants during one-on-one data-collection sessions during their stay. Since 2010, the school has played a key role in the training of over 200 new crystallographers and has

remote control, with the remaining $30 \%$ going through the mail-in crystallography service.

\section{Industrial usage of the CMCF beamlines}

Over the past five years, industrial usage of the CMCF sector has seen a steady increase in the number of industrial clients from several sectors of industry. The usage of the CMCF-ID beamline has increased from $24 \%$ in 2015 to nearly $35 \%$ in 2020. A similar trend has been observed for the CMCF-BM beamline, where industrial usage grew from $5 \%$ to $11 \%$. The majority of industrial users of the $\mathrm{CMCF}$ beamlines are represented by the United States $(65 \%)$, followed by China (15\%), Canada (10\%) and the EU (10\%).

Industrial access to the CMCF sector comprises two modes of access: remote control and mail-in. In 2020 nearly $55 \%$ of industry-allocated beam time was used by remote users and over $45 \%$ used mail-in access to the facility. Not surprisingly, most of the CMCF-ID allocated shifts were used by pharmaceutical industry clients, while CMCF-BM was largely used by environmental and material science clients. Of the CMCF-BM shifts used by industry, $18 \%$ were devoted to the pharmaceutical industry, $35 \%$ to environmental science and $47 \%$ to material science.

\section{Scientific outcomes and training}

Over the years, the CMCF has seen the publication of over 700 peer-reviewed articles containing data collected at the facility, as well as over 1300 PDB depositions, 11 patents or patent applications and more than 150 Masters and $\mathrm{PhD}$ theses. Many high-impact scientific studies have been conducted by the CMCF user base in many areas of health research, including cancer research (Raman et al., 2019; Ishizawa et al., 2019), drug design (Petrilli et al., 2020), antibiotic resistance provided an opportunity for aspiring crystallographers to meet and establish new connections that are important for their careers.

\section{Other beamlines}

Other beamlines at the Canadian Light Source that support structural biology projects include the Mid Infrared Spectromicroscopy (Mid-IR; May et al., 2007), Biological X-ray

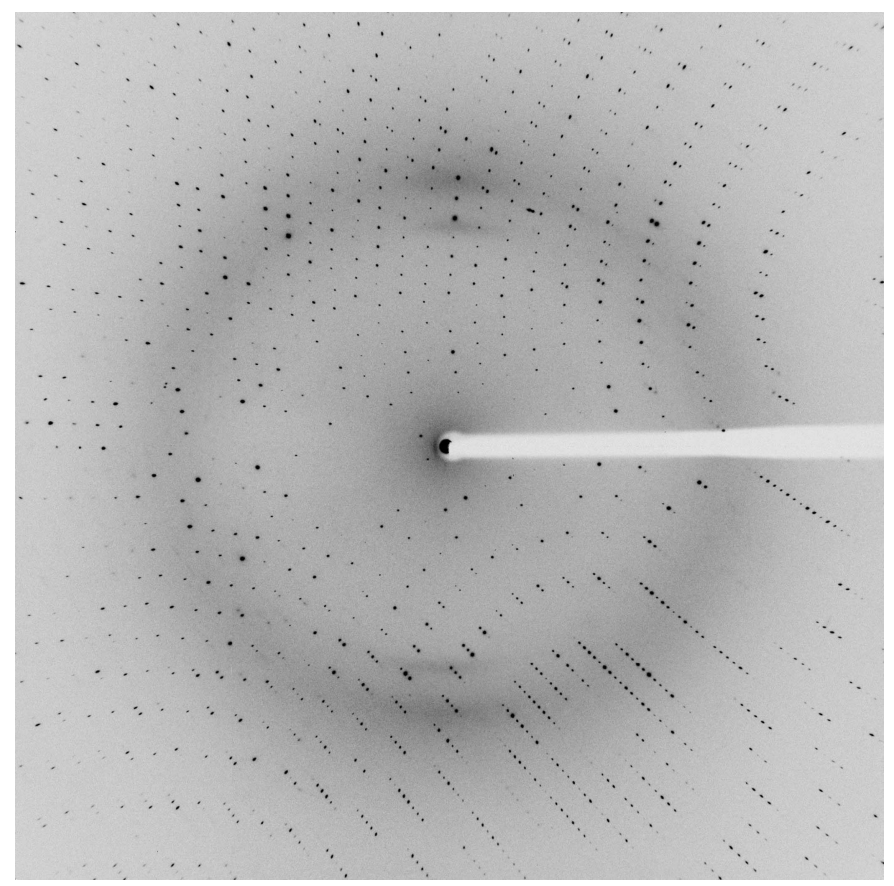

Figure 4

$1^{\circ} \mathrm{s}^{-1}$ diffraction pattern from a thaumatin crystal using a $100 \mu \mathrm{m}$ aperture in high-flux mode on CMCF-BM. 
Absorption Spectroscopy (BioXAS; Grochulski et al., 2017) and Biomedical Imaging and Therapy (BMIT; Wysokinski $e t$ al. , 2013) beamlines. The Mid-IR beamline is a state-of-the-art Fourier-transform IR spectrometer and microscope which provides diffraction-limited spatial resolution to an everwidening range of infrared spectromicroscopy experiments. The BioXAS beamline can perform extended X-ray absorption fine structure (EXAFS) experiments on 3-4 p.p.m. solid samples and millimolar solutions, and also supports multiresolution X-ray fluorescence imaging on biological samples. Additionally, BMIT can perform X-ray computed tomography (CT) measurements at various spatial and temporal scales. Phase-enhanced imaging, multi-contrast imaging and $K$-edge subtraction and spectral imaging are also supported.

\section{Conclusion}

We here report on recent advances at the macromolecular crystallography beamlines of the Canadian Light Source. Since 2006, the CMCF has become an integral part of the Canadian macromolecular crystallographic community, playing an important role in the development of a new generation of crystallographers through its annual CLS Mx Data Collection School, with over 200 trainees so far and over 150 graduate-level theses. The facility has also attracted the attention of industry, successfully retaining a client base that routinely makes use of up to $30 \%$ of available beamtime. The upgrade of CMCF-BM is complete and has enabled a sixfold decrease in the automounter duty-cycle time and an 18-fold increase in the photon flux at $8.15 \mathrm{keV}$ using multi-layer optics. Initial data sets revealed that despite the higher energy bandwidth, the multi-layer optics produce similar or better quality data sets when compared with the $\mathrm{Si}(111)$ optics at the same energy. The CMCF-ID upgrade is still in progress but is expected to be completed by 2021 . The updated CMCF-ID will enable high-flux micro-beam capabilities at the Canadian Light Source and these developments will allow the facility to effectively handle more challenging samples from a growing Canadian structural biology community.

\section{Acknowledgements}

The authors are grateful to the CMCF Beamline Advisory Team for their support and guidance and to Russ Berg, Shawn Carriere, Curtis Mullin, Drew Bertwistle and Raghu Koneru for engineering and software support. We would also like to acknowledge Aina Cohen, Jinhu Song and the other staff of the MX group at SSRL for assistance with the SAM Automounter control software.

\section{Funding information}

Funding for this research was provided by: Canada Foundation for Innovation; Natural Sciences and Engineering Research Council of Canada; National Research Council Canada; Canadian Institutes of Health Research; Government of Saskatchewan; University of Saskatchewan.

\section{References}

Caveney, N. A., Caballero, G., Voedts, H., Niciforovic, A., Worrall, L. J., Vuckovic, M., Fonvielle, M., Hugonnet, J. E., Arthur, M. \& Strynadka, N. C. J. (2019). Nat. Commun. 10, 1849.

Fodje, M., Grochulski, P., Janzen, K., Labiuk, S., Gorin, J. \& Berg, R. (2014). J. Synchrotron Rad. 21, 633-637.

Fodje, M., Janzen, K., Berg, R., Black, G., Labiuk, S., Gorin, J. \& Grochulski, P. (2012). J. Synchrotron Rad. 19, 274-280.

Grochulski, P., Fodje, M., Labiuk, S., Wysokinski, T. W., Belev, G., Korbas, M. \& Rosendahl, S. M. (2017). Nucl. Instrum. Methods Phys. Res. B, 411, 17-21.

Grochulski, P., Fodje, M. N., Gorin, J., Labiuk, S. L. \& Berg, R. (2011). J. Synchrotron Rad. 18, 681-684.

Ishizawa, J., Zarabi, S. F., Davis, R. E., Halgas, O., Nii, T., Jitkova, Y., Zhao, R., St-Germain, J., Heese, L. E., Egan, G., Ruvolo, V. R., Barghout, S. H., Nishida, Y., Hurren, R., Ma, W., Gronda, M., Link, T., Wong, K., Mabanglo, M., Kojima, K., Borthakur, G., MacLean, N., Ma, M. C. J., Leber, A. B., Minden, M. D., Houry, W., Kantarjian, H., Stogniew, M., Raught, B., Pai, E. F., Schimmer, A. D. \& Andreeff, M. (2019). Cancer Cell, 35, 721-737.

Kabsch, W. (2010). Acta Cryst. D66, 125-132.

Liebschner, D., Afonine, P. V., Baker, M. L., Bunkóczi, G., Chen, V. B., Croll, T. I., Hintze, B., Hung, L.-W., Jain, S., McCoy, A. J., Moriarty, N. W., Oeffner, R. D., Poon, B. K., Prisant, M. G., Read, R. J., Richardson, J. S., Richardson, D. C., Sammito, M. D., Sobolev, O. V., Stockwell, D. H., Terwilliger, T. C., Urzhumtsev, A. G., Videau, L. L., Williams, C. J. \& Adams, P. D. (2019). Acta Cryst. D75, 861-877.

May, T., Ellis, T. \& Reininger, R. (2007). Nucl. Instrum. Methods Phys. Res. A, 582, 111-113.

McLeod, B., Miura, K., Scally, S. W., Bosch, A., Nguyen, N., Shin, H., Kim, D., Volkmuth, W., Rämisch, S., Chichester, J. A., Streatfield, S., Woods, C., Schief, W. R., Emerling, D., King, C. R. \& Julien, J.-P. (2019). Nat. Commun. 10, 4328.

Petrilli, W. L., Adam, G. C., Erdmann, R. S., Abeywickrema, P., Agnani, V., Ai, X., Baysarowich, J., Byrne, N., Caldwell, J. P., Chang, W., DiNunzio, E., Feng, Z., Ford, R., Ha, S., Huang, Y., Hubbard, B., Johnston, J. M., Kavana, M., Lisnock, J. M., Liang, R., Lu, J., Lu, Z., Meng, J., Orth, P., Palyha, O., Parthasarathy, G., Salowe, S. P., Sharma, S., Shipman, J., Soisson, S. M., Strack, A. M., Youm, H., Zhao, K., Zink, D. L., Zokian, H., Addona, G. H., Akinsanya, K., Tata, J. R., Xiong, Y. \& Imbriglio, J. E. (2020). Cell. Chem. Biol. 27, $32-40$.

Raman, S., Beilschmidt, M., To, M., Lin, K., Lui, F., Jmeian, Y., Ng, M., Fernandez, M., Fu, Y., Mascall, K., Duque, A., Wang, X., Pan, G., Angers, S., Moffat, J., Sidhu, S. S., Magram, J., Sinclair, A. M., Fransson, J. \& Julien, J.-P. (2019). Proc. Natl Acad. Sci. USA, 116, 6812-6817.

Wysokinski, T. W. D., Chapman, G., Adams, M., Renier, P., Suortti, P. \& Thomlinson, W. (2013). J. Phys. Conf. Ser. 425, 072013. 